\title{
Effects of decline and/or air pollution on the terpene metabolism of Picea abies needles
}

\author{
A. Saint-Guily \\ Laboratoire de Physiologie Cellulaire Végétale, CNRS UA568, Université de Bordeaux I, 33405 \\ Talence Cedex, France
}

\section{Introduction}

The terpene metabolism (mevalonic acid pathway) is a secondary metabolism present in all plants. Terpenes are elaborated by successive condensation of isoprene units $\left(C_{5}\right) . C_{10}$ and $C_{15}$ terpene molecules are the main constituents of the volatile oils. These volatile terpenes are formed in secretory systems. Leucoplasts, nongreen plastids (Carde, 1984), are involved in their synthesis (Gleizes et al., 1983). In conifer needles, these plastids are localized in the epithelial cells of the subepidermal resin ducts. In Picea abies needles, the secretory ducts are longitudinal and discontinuous.

Forest decline is an important problem which appears in several countries in Europe and North America (McLaughlin, 1985). Most of the damaged forests are coniferous forests containing mainly spruce (Picea). Among the potential causes of forest decline, air pollution has received particular attention (McLaughlin, 1985). Previous studies have shown that the resin content of pine tissues greatly increases after mechanical or chemical injuries: wounding (Vassiliev and Carde, 1976), infestation by insects and infection by fungi (Cheniclet, 1987) or treatment with herbicides (Brown and $\mathrm{Nix}, 1975$ ).

The intention of this study was to elucidate a possible relationship between the stress factors and a variation in terpene metabolism.

\section{Materials and Methods}

Different samples of needles were collected in the spruce ( $P$. abies) stands which were located in the Donon forest where 3 decline classes were defined with respect to needle loss: class $2(0-10 \%$ needle loss), class $3 a(10-20 \%)$ and class $3 \mathrm{~b}$ (35-50\% with yellowish chlorosis). Needles of 3 consecutive yr from about 12 trees of each decline class were collected. The other samples of $\mathbf{5}$ yr old clones ("lac de Constance" (LC), "Gérardmer" (GER), "Istebna" (IST) were collected in the open top chambers of Montardon and Donon. These plants were placed under controlled conditions of air pollution which were equivalent to the pollution recorded in the Donon forest. The 3 clones were placed in air-filtered open top chambers or fumigated with ozone $\left(\mathrm{O}_{3}\right)$ or sulfur dioxide $\left(\mathrm{SO}_{2}\right)$ alone or a mixture. In Montardon, a mobile roof protects the trees from the rain.

Cytological observations were made with an electron microscope. RuBPCase was localized on ultrathin sections using immunogold labeling 
techniques (Shaw and Henwood, 1985). The leucoplastidial volume density ( $L V D)(\%$ of the cell volume occupied by leucoplasts) was estimated using a morphometric technique (Weibel, 1969).

For analytical studies, oxygenated and hydrocarbon terpene fractions were separated on a silica column after pentane extraction and analyzed with a gas chromatograph, using an apolar capillary column (Belingheri et al., 1988). A 'desorption concentration injection' system (DCl, Delsi, France) was also used. About 5 needles were inserted into a heating block. The volatile compounds were swept by a carrier gas and trapped in a tenax cartridge attached directly to the injector of the gas chromatographic apparatus (the injection consists of a thermal desorption of the trapped compounds).

The statistical evaluations of our data included an analysis of variance and a technique for testing all differences between pairs of means (multiple comparisons among pair of means: $T$ method) (Spjotvoll and Stoline, 1973; Sokal and Rohlf, 1981).

\section{Cytological studies}

\section{Study of the leucoplastidome}

\section{Leucoplastidome and decline}

In the Donon forest, the mean volume densities of leucoplasts were $10 \%$ for the 'healthy' trees and 15, 18 and $19 \%$ for the classes $2,3 \mathrm{a}$ and $3 \mathrm{~b}$, respectively. Results of the $T^{\prime}$-method are presented in Table 1 . The pairs of damaged classes (2-3a, $2-3 b$ and $3 a-3 b$ ) did not show any significant differences between each other. But a significant difference did exist between the $L V D$ of healthy trees and the $L V D$ of all the other classes.

\section{Leucoplastidome and air pollution}

For spruces fumigated with air poliutants in open top chambers, the estimation of
Table I. Pairs comparison of the decline classes as regards the leucoplastidial volume density: ' $T$ '-method'.

\begin{tabular}{lll}
\hline $\begin{array}{l}\text { Compared } \\
\text { classes }\end{array}$ & $\mathrm{T}^{\prime}$ & $\begin{array}{l}\text { Significant difference } \\
\text { if } \mathrm{T}^{\prime}>0 \mathrm{r}=\mathrm{Q}^{\prime} \text { 0.05(4.120) }\end{array}$ \\
\hline healthy 2 & 3.700 & + \\
heaithy 3a & 5.791 & ++ \\
healthy 3b & 6.763 & +++ \\
2-3a & 2.359 & - \\
2-3b & 3.149 & - \\
3a-3b & 1.106 & - \\
\hline
\end{tabular}

For each pair of classes the sample statistic $T^{\prime}$ was calculated.

${ }^{a}$ Critical value of the studentized augmented range table: $Q_{0.05}^{\prime}(4.120)=3.685$

the LVD was different between the trees from Montardon and these from Donon experiments.

In the first case, the LVD was about $20 \%$ of the cell volume and no significant difference between trees fumigated with $\mathrm{O}_{3}, \mathrm{SO}_{2}, \mathrm{O}_{3}+\mathrm{SO}_{2}$ or charcoal-filtered air could be shown.

Samples from Donon showed a higher LVD for fumigated trees (24\%) than for non-fumigated ones (13\%).

Study of the chloroplasts (RuBPCase labeling)

About 20 plastids were investigated on ultrathin sections for each decline state. Variance analysis of these results verified that RuBPCase labeling was not equivalent for the different classes. The average densities of the gold labeling (number of gold particles per $\mu \mathrm{m}^{2}$ of chloroplast section) was 96 for 'healthy' trees and 126, 121 and 59 for classes 2, 3a and 3b, respectively. Only the $3 \mathrm{~b}$ state showed significant differences with the 3 other classes (Table II). 
Table II. Pairs comparison of the decline classes as regards the RuBPCase density: ' $T$ ' method'.

\begin{tabular}{lll}
\hline $\begin{array}{l}\text { Compared } \\
\text { classes }\end{array}$ & $\mathrm{T}^{\prime}$ & $\begin{array}{l}\text { Significant difference } \\
\mathrm{T}^{\prime}>0 \mathrm{O}=\mathrm{Q}^{\prime}{ }_{0.05(4.60)}{ }^{\mathrm{a}}\end{array}$ \\
\hline $\begin{array}{l}\text { healthy 2 } \\
\text { healthy 3a }\end{array}$ & 4.208 & + \\
healthy 3b & 5.308 & - \\
$2-3 \mathrm{a}$ & 0.572 & + \\
2-3b & 9.504 & +- \\
3a-3b & 7.979 & ++ \\
\hline
\end{tabular}

For each pair of classes, the sample statistic $T^{\prime}$ was calculated.

a Critical value of the studentized augmented range table: $Q_{0.05(4.60)}^{\prime}=3.737$.

\section{Terpene composition}

\section{Donon forest: declined trees}

No significant variation of terpene composition was observed in correlation with the decline.

\section{Open top chambers}

The investigations of needle samples of IST from the Donon forest showed a constant terpene hydrocarbon composition. In a polluted atmosphere, the proportion of bornyl acetate increased, while the proportion of camphor decreased. The 2 other clones (GER and LC) presented larger proportions of pinene and camphene and smaller proportions of limonene in needles of fumigated trees.

In the Montardon forest, the terpene composition of IST and LC was independent of air pollution conditions during the growth of the needles. For GER the concentrations of limonene and bornyl acetate seemed to be different between fumigated and non-fumigated trees. However, on fully grown needles, differences in the terpene composition were no longer observed. The varying terpene patterns found in these needles were dependent upcn the origin of the plants and not upon on the conditions of pollution.

\section{Discussion}

There are significant differences between the leucoplastidial volume density of 'healthy' and damaged trees of the Donon forest. But the increase of the $L V D$ and the decline of the trees did not seem to correlate to any variation of terpene composition in the needles of $P$. abies. Therefore, the LVD differences could be due to a shifting of cell differentiation in relation to the different localizations of the healthy and damaged tree classes. The lower labeling density of RuBPCase for the trees with bleached needles (state $3 b$ ) would be due to an irreversible disturbance of the metabolism. But another experiment with a larger plastid sampling must be done in order to confirm this first result.

In the open top chambers of the Montardon forest, there was no change of the leucoplastidial density and of the composition of the terpene hydrocarbons. In needle samples from the Donon open top chambers, the decreased LVD was correlated to changes in the composition of the oxygenated compounds for IST. The terpene composition of GER and LC was also modified. These results suggest that fumigation and natural rain are necessary to produce a modification of the terpene metabolism under controlled conditions.

\section{References}

Belingheri L., Pauly G. \& Gleizes M. (1988) Terpene hydrocarbons from Citrofortunella mitis fruits and leaves. Plant Physiol. Life Sci. Adv. 7, $101-103$ 
Brown C.L. \& Nix L.E. (1975) Uptake and transport of paraquat in slash pine. For. Sci. 21, 359-364

Carde J.P. (1984) Leucoplasts: a distinct kind of organelles lacking typical 705 ribosomes and free thylakoids. Eur. J. Cell Biol. 34, 18-26

Cheniclet C. (1987) Effects of wounding and fungus inoculation on terpene producing systems of maritime pine. J. Exp. Bot. 38, 15571572

Gleizes M., Pauly G., Carde J.P., Marpeau A. \& Bernard-Dagan C. (1983) Monoterpene hydrocarbon biosynthesis by isolated leucoplasts of Citrofortunella mitis. Planta 159, 373-381

McLaughlin S.B. (1985) Effects of air pollution on forests. A critical review. Air Pollut. Control Assoc. 35, 512-534

Shaw P.J. \& Henwood J.A. (1985) Immuno-gold localization of cytochrome $t$, light-harvesting complex, ATP synthase and ribulose 1,5-bisphosphate carboxylase/oxygenase. Planta 165, 333-339

Sokal R.R. \& Rohlf F.J. (1981) In: Biometry. W.H. Freeman and Co., New York, pp. 859

Spjotvoll E. \& Stoline M.R. (1973) An extension of $T$-method of multiple comparison to include the cases with unequal sample sizes. J. Am. Stat. Assoc. 68, 975-978

Vassiliev A.E. \& Carde J.P. (1976) Effects du gemmage sur l'ultrastructure des cellules sécrétrices des canaux de l'écorce des tiges de Pinus sylvestris L. et Picea abies (L.) Karst. Protoplasma 89, 41-48

Weibel E.R. (1969) Stereological principles for morphometry in electron microscopic cytology. Int. Rev. Cytol. 26, 235-302 